\title{
Constituição de uma Rede Colaborativa de Pesquisa: o Observatório Nacional de Educação Especial (ONEESP) ${ }^{1}$ \\ Enicéia Gonçalves Mendes ${ }^{2}$ \\ Fabiana $\mathrm{Cia}^{3}$
}

\section{RESUMO}

Constituição de uma Rede Colaborativa de Pesquisa: o Observatório Nacional de Educação Especial (ONEESP). Apesar do crescimento expressivo da produção científica na área de Educação Especial, o conhecimento que vem sendo produzido parece ter pouco impacto na definição dos caminhos que as políticas educacionais para a escolarização de crianças e jovens com necessidades educacionais especiais têm assumido no país. Isso acontece, entre outras razões, pela falta de articulação entre pesquisadores e seus projetos, resultando em produções reiterativas, com limitadas implicações para as práticas e políticas. Considerando a importância atual da articulação da produção científica em contextos de redes colaborativas de pesquisa, a presente proposta visa a apresentar o histórico de criação do Observatório Nacional de Educação Especial (Oneesp), cujo foco será a produção de estudos integrados sobre políticas e práticas direcionadas para a questão da inclusão escolar de estudantes com necessidades educacionais especiais na realidade brasileira. O Oneesp atualmente é constituído por 211 pesquisadores provenientes de 16 estados brasileiros, representantes de 24 universidades e de 20 programas de pós-graduação, que estão conduzindo um estudo em rede cujo delineamento misto envolverá estudos locais nos municípios baseados na metodologia da pesquisa colaborativa, que tem como foco produzir simultaneamente conhecimento e formação para professores especializados que atuam em salas de recursos multifuncionais.

Palavras-chaves: Educação Especial; pesquisa colaborativa; formação de professores.

\section{ABSTRACT}

Constitution of a Collaborative Network Research: the National Special Education Obervatory (NSEO). In spite of the significant growth of scientific production on Special Education area, it seems that it does not have a great impact on educational policies for students with special educational needs. This happens, among other reasons, because there is a lack of coordination between researchers and their projects, resulting in reiterative production with limited implications for policies and practices. Considering the current importance of scientific networks in the context of collaborative research, this work aims to present the National Special Education Observatory (NSEO) history, whose focus is to produce integrated studies on

1 Pesquisa financiada pela CAPES e pelo CNPq.

2 Professora Ajunta do Programa de Pós-Graduação em Educação Especial da Universidade Federal de São Carlos (UFScar). E-mail: egmendes@ufscar.br

3 Professora Ajunta do Programa de Pós-Graduação em Educação Especial da Universidade Federal de São Carlos (UFScar).E-mail: fabianacia@hotmail.com 
policies and practices in order to promote the educational school inclusion of students with special educational needs. Now the NSEO has 211 associate researchers from 16 Brazilian states, representing 24 universities and 20 graduate programs. They are conducting a network study involving local municipalities, based on the methodology of collaborative research that focuses on producing knowledge and specialized training for teachers who deal with multifunctional resource rooms .

Key works: Special Education; collaborative research; teacher education.

\section{INTRODUÇÃO}

A demanda pela constituição de redes colaborativas de pesquisa em Educação Especial tem emergido em vários encontros de pesquisadores ao longo dos últimos cinco anos e vários grupos interinstitucionais de pesquisa têm sido constituídos em busca de parcerias colaborativas de produção de conhecimento. O Observatório Nacional de Educação Especial (Oneesp) é uma dessas redes que teve sua proposta original delineada pelo Grupo de Pesquisa sobre Formação de Recursos Humanos (GP-Foreesp) da Universidade Federal de São Carlos.

O GP-Foreesp foi constituído em 1997 com o intuito de produzir estudos que contribuíssem para o processo de universalização do acesso e melhoria da qualidade do ensino oferecida à população-alvo da Educação Especial. Desde o início, a decisão de pesquisa pela questão da inclusão escolar foi adotada pelo grupo, entre outros motivos, porque parte-se do pressuposto de que a construção de sistemas educacionais inclusivos seria a única alternativa para melhorar o equacionamento do problema do escasso acesso à escola e da baixa qualidade da Educação Especial no país. Nesse sentido, as principais vertentes dos estudos do GP-Foreesp têm sido as políticas voltadas para a escolarização da pessoa com deficiência e a questão da formação de profissionais para atuar nessa perspectiva da inclusão escolar. Em geral, a sistemática de produção de conhecimento no âmbito do grupo parte de um projeto de grande porte que funciona como guarda chuva e de subprojetos a ele articulados, tais como pós-doutorado, doutorado, mestrado e iniciação científica. De 1997 até o presente, foram concluídos no âmbito do GP-Foreesp mais de 50 estudos sobre inclusão escolar e as conclusões destes projetos apontaram para a necessidade de construção de redes colaborativas de pesquisa com a finalidade de buscar uma maior articulação entre e pesquisa e a política de inclusão escolar.

Especificamente, a ideia de criação do Oneesp fortaleceu-se em 2009, quando foi lançado o Edital do Programa de Apoio à Educação Especial - PROESP - CAPES/2009. Considerando que a UFSCar constituía-se na época em um dos principais centros de referência de produção do conhecimento e formação na área de Educação Especial, em função do Programa de Pós- 
Graduação em Educação Especial- PPGEEs, havia o entendimento que a UFSCar deveria submeter uma proposta para o citado edital. O projeto submetido e aprovado foi elaborado pelo GP-Foreesp e tinha como objetivo, tanto induzir a produção de conhecimento e de formação de recursos humanos na temática da educação inclusiva no âmbito do próprio programa de pósgraduação, quanto fomentar a criação de uma rede de pesquisadores nacionais que comporiam o “Observatório Nacional de Educação Especial” (Oneesp). Com esse projeto esperava-se ampliar e melhorar a qualidade da produção do PPGEEs sobre educação inclusiva e inserir esta produção em um contexto de rede de cooperação científica nacional, visando ao aprimoramento das pesquisas e das políticas vinculadas à questão da educação inclusiva no país.

Entretanto, apesar da aprovação deste projeto para o referido edital, não foi possível captar recursos suficientes para a constituição da rede de pesquisa pretendida e novas ideias foram então sendo aportadas pelos integrantes do GP-Foreesp com o intuito de planejar um projeto de pesquisa sobre inclusão escolar que fosse capaz de aglutinar interesses de vários pesquisadores e de captar recursos das agências para a constituição da rede nacional. O lançamento do edital do Programa Observatório da Educação - Edital 2010 - Fomento a Estudos e Pesquisas em Educação (Edital No 38/2010/Capes/Inep) ofereceu uma nova oportunidade de concretização do Oneesp, mas para isso seria necessário construir um projeto preliminar para agregar pesquisadores da área. A seguir descreveremos como este projeto foi se delineando.

\section{Definição do tema para o projeto inaugural do Oneesp}

A temática da inclusão escolar já era de interesse do grupo de pesquisa, que já desenvolvia uma longa e intensa agenda de estudos sequenciais sobre essa questão e era também um tema emergente na área de Educação Especial porque os estudantes com necessidades educacionais especiais (NEEs) fazem parte das estatísticas de crianças sem acesso à escolarização básica e nos poucos países que lhes garantem acesso à escola, os caminhos encontrados para isso são diversificados.

Analisando as políticas educacionais dos países europeus a European Agency for Development in Special Needs Education (2003) encontrou três modelos básicos de provisões de escolarização para estes estudantes, a saber: de via única, de vias mistas e de vias paralelas.

O modelo de via única (“one track approach”) é aquele com políticas e práticas orientadas para a escolarização de quase todos os alunos num único sistema comum de ensino, mas agregando um conjunto importante de serviços de apoio, como pode ser observado no Chipre, na Espanha, na Grécia, na Islândia, na Itália, na Noruega, em Portugal e na Suécia. O segundo modelo agrupa os 
países que seguem vias mistas (“multi track approach”) oferecendo uma diversidade de serviços para a escolarização dessa população em ambos os sistemas (Educação Especial e Educação Comum) e pode ser observado nos seguintes países: Dinamarca, França, Irlanda, Luxemburgo, Áustria, Finlândia, Reino Unido, Latvia, Liechtenstein, República Tcheca, Estônia, Lituânia, Polônia, Eslováquia e Eslovênia. O terceiro modelo é o de via paralela onde há dois sistemas educacionais completamente distintos ("two track approach"), os alunos com NEEs são geralmente colocados em escolas separadas, não seguem o currículo comum de seus pares sem necessidades educacionais especiais e sua escolarização pode até ser regida por legislação diferente. Este seria, por exemplo, o caso da Suíça e da Bélgica.

Entretanto, independentemente desses diferentes caminhos históricos, na atualidade o direito dos alunos com NEEs em frequentar uma classe comum da escola regular de seu bairro, para onde eles iriam se não fossem considerados "diferentes", tem sido uma prática cada vez mais defendida na ampla maioria dos países e muitas reformas educacionais nos sistemas públicos de ensino estão sendo conduzidas para este alvo. Além da questão do direito, imperam também razões éticas, considerando que não há motivos fortes que justifiquem a segregação escolar indiscriminada destes alunos e, por isso, no mundo todo os sistemas educacionais têm procurado reestruturar-se para responder também às necessidades de todos os seus alunos.

No campo da Educação Especial, o termo educação inclusiva refere-se justamente a este movimento que busca criar escolas que caminhem ao encontro das necessidades de todos os alunos, que estabeleçam comunidades de aprendizagem para estudantes com e sem limitações, que oportunizem serem educados juntos em classes comuns compatíveis em idade e em escolas da vizinhança (FERGUSON, 1996). Entretanto, o termo educação inclusiva refere-se a uma população abrangente que não se restringe à tradicional população referida para a Educação Especial, e para evitar confusões conceituais decorrentes da redução do conceito de educação inclusiva à educação de estudantes com NEEs, temos adotado por convenção o termo "inclusão escolar” em referência à questão específica da escolarização dessa parcela da população-alvo da Educação Especial.

Embora a questão da inclusão escolar não devesse ser tão controvertida, o tema tem despertado um debate fervoroso nos últimos 30 anos, em parte porque esta filosofia não afeta apenas os estudantes com NEEs, mas implica também em modificar a educação de todos os alunos. E é na necessidade de reestruturar a escola brasileira que reside o fascínio desta filosofia que promete dinamizar uma escola básica que tem um dos piores desempenhos do planeta, mas que ao mesmo tempo representa um enorme desafio frente à complexidade que este tipo de reforma impõe a um sistema educacional que resiste a mudanças. 
Wang, Reynolds e Walberg (1995) consideram que na atualidade, o conhecimento científico acumulado sobre a educação de crianças e jovens com NEEs permite reconhecer no mínimo três tipos diferenciados de programas educacionais para essa parcela da população.

Um primeiro tipo de programa seria a versão de uma boa escola, com educação de qualidade para todos os tipos de estudantes. Tal tipo de programa poderia prevenir a ocorrência de dificuldades no processo de escolarização tanto para os alunos já considerados de risco, quanto para qualquer tipo de aluno. Especificamente em relação ao ensino especial, esse tipo de programa poderia beneficiar os estudantes com dificuldades específicas de aprendizagem, deficiência intelectual leve, distúrbios emocionais, dificuldades de linguagem, distúrbios leves de conduta e mesmo aqueles pertencentes a grupos minoritários em desvantagem cultural. A população para tal programa é estimada em cerca de $75 \%$ do alunado da Educação Especial e por ser maioria numérica, essa população tem sido referida na literatura como aquela das "dificuldades de alta incidência". Para tais alunos, o ensino necessário não é diferente em tipo, mas pode ser em magnitude ou intensidade com o intuito de responder às necessidades específicas de cada estudante. Nesse caso, as intervenções mais bem sucedidas também têm sido aquelas que começam cedo ou que desde a fase prevista na Educação Infantil oferecem acomodações no currículo, as quais são mantidas ao longo dos anos de escolarização. Tal tipo de programa tem implicações tanto para a organização escolar, em virtude da necessidade de serviços de apoio complementares, quanto para a formação de professores para os serviços educacionais regulares e os de apoio.

Um segundo conjunto de programas inclui tipos efetivamente distintos de práticas instrucionais que são tradicionalmente encontradas na escolar regular, tais como o ensino do Braille para cegos, de língua de sinais para surdos, de sistemas de comunicação alternativos para alunos sem produção de fala, etc. Esse tipo de programa requer competências altamente especializadas do professor e um tipo de organização escolar ainda indefinida. Existe inclusive, na literatura, muita controvérsia sobre os tipos mais adequados de arranjos educacionais para esse tipo de programa, cuja população alvo seria a de alunos com deficiências auditivas, visuais, intelectuais (de nível moderado e até severo) e aqueles com distúrbios acentuados de linguagem, que correspondem a cerca de 20 a 25\% do alunado da Educação Especial.

O terceiro conjunto de programas destina-se a alunos que apresentam dificuldades realmente acentuadas e em vários domínios, nos quais tanto a organização escolar quanto o conhecimento sobre instrução que se têm, são ainda muito limitados. Tal programa seria necessário para uma minoria da população do ensino especial e o atendimento educacional previsto iria requerer mais do que serviços de escolarização, pois deveria envolver coordenação com outras agências de prestação de serviços da comunidade e particularmente um intensivo envolvimento da família. 
E como esta demanda pelos três tipos de programas pode ser equacionada no contexto das políticas de inclusão escolar? Seria possível e viável prover esses três tipos de programa nas escolas comuns? E mais do que isso: seria de fato a melhor opção escolarizar qualquer estudante com necessidades educacionais especiais em tempo integral numa classe comum com os colegas de mesma idade?

De modo geral, tem havido pouca controvérsia quando se fala de inclusão escolar no caso dos alunos com dificuldades leves, que compõe cerca de $80 \%$ dos alunos com necessidades educacionais especiais que demandam apenas uma escolarização apoiada e uma escola de boa qualidade. Entretanto, o consenso diminui quando se trata dos cerca de $20 \%$ de alunos referidos para o segundo e terceiro tipo de programa que exigem especificidades de ensino que não são necessariamente compatíveis com a escolarização em classe comum.

Paralelo a um contexto de extrema complexidade que engendra a discussão sobre as políticas de inclusão escolar, aparece ainda outro complicador para desviar o debate de seu cerne. Como bem apontou Sowell (1995), há no presente uma divisão ideológica onde de um lado estão os "iluminados" que advogam com mais ênfase em favor da inclusão total, mais radical e que tem sido hegemônicos na definição dos caminhos da política, e do outro, os "ignorantes", uma condição atribuída aos que manifestam qualquer espécie de resistência, cautela ou mesmo de rejeição radical a esse tipo de proposta.

E tem sido neste contexto que, uma vez instituída uma proposta política na perspectiva da educação inclusiva, qualquer evidência empírica que aponte para impactos inesperados passa a ser explicada em função de um conflito entre as visões, batalhas entre "nós" e "eles", como se estivéssemos medindo as forças da moralidade $\mathrm{x}$ imoralidade, entre justos $\mathrm{x}$ injustos, e não à procura do avanço em nossas proposições teóricas, práticas e políticas (KAVALE; FORNESS, 2000).

O que torna este contexto perigoso não é apenas o fato de que as resistências podem provocar ou mesmo justificar as descontinuidades das propostas políticas, ou que o efeito obtido possa ser um retrocesso à história até então conquistada, mas também o fato de que, ao se fechar o olho para as evidências científicas, perde-se também a possibilidade de descobrir e garantir como promover avanços nas políticas e práticas. 
Assim, é fato que a área da Educação Especial passa por fortes tensões entre aqueles que apontam para a necessidade de uma mudança radical e outros que recomendam uma aproximação mais cautelosa, pautada em mudanças fundamentadas em análises empíricas e em considerações históricas (MEREDITH; UNDERWOOD, 1995; DORN; FUCHS; FUCHS, 1996, MENDES, 2006).

A ideia de que o melhor locus para a escolarização de estudantes com necessidades educacionais especiais é na classe comum da escola regular, não é nova e emergiu em meados da década de 70, de modo que temos hoje um acúmulo de mais de 30 anos de pesquisas investigando essa possibilidade. Em síntese, o que esta literatura tem indicado é que o processo de inclusão escolar parece não ser algo que simplesmente acontece espontaneamente, mas algo que requer pensamento cuidadoso e bastante preparo. Muito ainda não é conhecido, mas já se sabe que o impacto deste tipo de prática sobre a educação comum não é uniformemente encorajadora e que é preciso uma implementação cuidadosa, debatida e monitorada (DOWNING et al., 1997; IDOL, 1997).

Neste contexto, cabe à Educação Especial, enquanto área de conhecimento científico, aprofundar o conhecimento sobre o assunto produzindo mais e mais pesquisas sobre a temática da inclusão escolar, sem perder de vista que sua verdadeira missão é a de investigar como prover a melhor educação possível para as crianças e jovens com necessidades educacionais especiais. E esse foi o pressuposto assumido pelo Oneesp: analisar, no caso do Brasil, como tem sido planejada e conduzida a política de inclusão escolar na realidade brasileira.

\section{A política de inclusão escolar no contexto brasileiro}

A partir da Constituição Federal de 1988 e da Lei de Diretrizes e Bases da Educação (nº 9394/96), foram reforçados os pressupostos da escola inclusiva, que aparecem referendados nas iniciativas com vistas à reforma do sistema educacional brasileiro. No que tange às crianças e jovens com NEEs, está garantida legalmente a matrícula nas escolas públicas regulares, o que em tese poderá permitir a ampliação das oportunidades educacionais e universalizar o acesso à educação para esse contingente da população. Entretanto, a garantia de permanência e, consequentemente, o direito à educação e ao sucesso escolar somente serão possíveis se a escola comum conseguir responder às necessidades educacionais especiais desses alunos, uma vez que a igualdade de condições, nesse caso, não significa equiparação de oportunidades para acessar o conhecimento produzido e acumulado pela cultura. 
A Lei de Diretrizes e Bases da Educação Nacional (LDBEN n 9.394/96), ao tratar do processo de escolarização de pessoas com NEEs, sinaliza, em seu artigo 58, que a Educação Especial deve ser oferecida, preferencialmente, na rede regular de ensino. Esses movimentos têm levado tanto a União, quanto Estados e Municípios a adotarem políticas públicas que garantam o direito à educação para as pessoas com deficiência, transtornos globais do desenvolvimento e altas habilidades/superdotação. Esta mesma lei, em seu artigo 58, convoca-nos a reorganizar os sistemas de ensino com vistas a assegurar currículos, métodos, técnicas, recursos educativos, organizações específicas, profissionais especialistas e professores capacitados para garantir o desenvolvimento educacional desses alunos.

O documento "Política Nacional de Educação Especial na Perspectiva da Educação Inclusiva" (PNEE-EI) do MEC (BRASIL, 2008) recomenda a implementação de políticas públicas para que alunos com deficiência, transtornos globais do desenvolvimento e altas habilidades/ superdotação tenham garantido o acesso, a participação e o aprendizado nas escolas comuns. Esse documento, além de definir os estudantes elegíveis para a Educação Especial, também reforça os princípios e fundamentos das escolas inclusivas.

O Decreto $n^{\circ}$ 6.571/08 (BRASIL, 2008) dispõe sobre o atendimento educacional especializado (AEE), definindo este sistema de apoio à escolarização de alunos com NEEs como sendo:

o conjunto de atividades, recursos de acessibilidade e pedagógicos organizados institucionalmente, prestado de forma complementar ou suplementar à formação dos alunos no ensino regular (BRASIL/ SEESP, 2008, \$1).

$\mathrm{O}$ artigo $3^{\circ}$ desse decreto especifica que o MEC prestará apoio técnico e financeiro às seguintes ações voltadas à oferta do atendimento educacional especializado, entre outras que atendam aos objetivos previstos neste Decreto:

- implantação de salas de recursos multifuncionais (grifo nosso);

- formação continuada de professores para o atendimento educacional especializado;

- formação de gestores, educadores e demais profissionais da escola para a educação inclusiva;

- adequação arquitetônica de prédios escolares para acessibilidade;

- elaboração, produção e distribuição de recursos educacionais para a acessibilidade;

- estruturação de núcleos de acessibilidade nas instituições federais de educação superior. 
Ao definir a função do AEE, o documento da PNEE-EI estabelece como sendo:

[...] identificar, elaborar e organizar recursos pedagógicos e de acessibilidade que eliminem as barreiras para a plena participação dos alunos, considerando suas necessidades específicas (BRASIL, 2008, p.10).

Em relação aos níveis de ensino, a PNEE-EI prevê que o AEE seja ofertado:

a) $\mathrm{Na}$ Educação Infantil, incluindo os serviços de estimulação precoce.

b) Na etapa da escolaridade obrigatória, no Ensino Fundamental, com a ressalva de que deve "ser realizado no turno inverso ao da classe comum, na própria escola ou centro especializado que realize esse serviço educacional” (BRASIL, 2008, p. 1).

c) Na modalidade de Educação de Jovens e Adultos e educação profissional, visando a ampliar oportunidades de escolarização, formação para ingresso no mundo do trabalho e efetiva participação social.

d) Na educação indígena, do campo e quilombola deve ser assegurado que os recursos, serviços e o AEE estejam presentes nos projetos pedagógicos construídos com base nas diferenças socioculturais desses grupos.

e) $\mathrm{Na}$ educação superior, estas ações envolvem o planejamento e a organização de recursos e serviços para a promoção da acessibilidade arquitetônica, nas comunicações, nos sistemas de informação, nos materiais didáticos e pedagógicos, que devem ser disponibilizados nos processos seletivos e no desenvolvimento de todas as atividades que envolvam o ensino, a pesquisa e a extensão.

Adicionalmente, o Decreto no 6.571/08 (BRASIL, 2008) especifica que o AEE poderá ser oferecido pelos sistemas públicos de ensino ou pelas instituições especializadas e define as salas de recursos multifuncionais (SRMs) como ambientes dotados de equipamentos, mobiliários e materiais didáticos e pedagógicos para a oferta do atendimento educacional especializado.

Como vemos, a legislação educacional prescreve que o AEE deve se organizar preferencialmente pela oferta de "salas de recursos multifuncionais" (SRMs), para que alunos com NEEs não interrompam seus percursos escolares na classe comum, mas que ao mesmo tempo tenham supridas suas demandas de escolarização. Nesse sentido, a Secretaria de Educação Especial/MEC lançou no ano de 2005 o "Programa de Implantação de Salas de Recursos Multifuncionais" para apoiar os sistemas de ensino a criarem SRMs com materiais pedagógicos e de acessibilidade para a realização do AEE, complementar ou suplementar à escolarização. De acordo com dados disponibilizados pelo MEC, entre os anos de 2005 a 2009, foram oferecidas 15.551 salas de recursos multifuncionais a 4.564 municípios brasileiros, distribuídas em todos os estados e o Distrito Federal. O programa é destinado às escolas das redes estaduais e municipais de educação, 
com base nos alunos com NEEs registrados no Censo Escolar MEC/INEP. No entanto, nem sempre os dispositivos legais conseguem ser implementados na prática, visto a realidade complexa e dinâmica que envolve os sistemas escolares.

Estudos sobre políticas de inclusão escolar realizados em várias cidades dos estados do Espírito Santo (JESUS, 2008; 2009; GONÇALVES, 2010) e de São Paulo (PRIETO; SOUSA, 2007; TEIXEIRA, 2009; VELTRONE, 2010; GIL et al., 2010) têm indicado que ainda que pertencentes a um mesmo estado e submetidos a uma mesma política nacional e estadual, os municípios têm apresentado diferentes modelos de organização de serviços de apoio à escolarização de alunos com NEEs. Foram encontrados modelos baseados em salas de apoio/ reforço, na colaboração entre professores especializados e professores do ensino comum, no auxílio de estagiários contratados e, apenas mais recentemente, os modelos de apoio em SRMs conforme recomendação do MEC.

Nesse movimento diverso de cada município, há uma tendência de se forçar a padronização da política de inclusão escolar com a oferta de AEE baseado nas SRMs por parte do MEC, enquanto que a tendência atual de organização de serviços de apoio, tendo em vista a inclusão escolar na literatura da área, tem sido de manter uma estrutura cada vez mais diversificada de apoios e serviços para atender à população dos estudantes com NEES. No caso do Brasil, a opção política em relação às escolas públicas tem sido a de priorizar a chamada "sala de recurso multifuncional", uma espécie de "serviço tamanho único", quando ele deveria ser apenas mais um dos vários serviços disponíveis no sistema do contínuo dos serviços. Tal opção, entretanto, representa uma simplificação dos serviços de apoio, que não encontra sustentação na literatura da área de Educação Especial em termos de efetividade para atender às necessidades tão diversificadas deste alunado e as dúvidas que daí surgem são muitas, de modo que podemos questionar: será de fato este o melhor caminho? Pode o AEE desenvolvido no contraturno nas SRMs suprir as necessidades de todos os alunos com NEEs?

\section{Definindo questóes para o estudo}

Associados à questão da concepção simplificada da política dos sistemas de apoio à escolarização de alunos com NEEs, três outros grandes temas desafiam a atual política de inclusão escolar em nosso país e referem-se à questão da organização do atendimento educacional especializado nas SRMs, a formação de professores e a avaliação dos estudantes com NEEs. 
Em relação à organização do AEE nas SRMs, dada a recenticidade da proposta de implantação desses serviços e o crescimento do número de SRMs em todo o país, seria interessante investigar o ensino dos alunos com NEEs nesses espaços? Como os professores especializados respondem, em uma ou duas horas de atendimento em turno alternado, às necessidades diferenciadas das mais variadas crianças, que em geral, chegam à escola só aos seis anos de idade, sem requisitos mínimos e já com atrasos consideráveis no desenvolvimento? Como tem sido organizado o atendimento a alunos com idades e deficiências tão díspares? Que compreensão os professores têm do AEE oferecido em SRMs? Que relação existe entre o currículo da SRMs e das classes comuns que o aluno frequenta? Que limites e possibilidades oferecem as SRMs como serviço de apoio para todos os tipos de alunos?

Além do modelo de AEE baseado nas SRMs, a política de inclusão escolar brasileira tem ainda um segundo aspecto problemático que se refere à questão da avaliação do estudante com necessidades educacionais especiais (CAPELLINI, 2001; TANNUS-VALADÃO, 2010; VELTRONE, 2011). No campo da Educação Especial, a avaliação educacional é um processo que envolve coleta de dados para guiar tomadas de decisões com três finalidades distintas: identificar os alunos com NEEs e definir a elegibilidade aos serviços de apoio, planejar o ensino desses alunos através do desenvolvimento de um plano individualmente talhado para responder às necessidades do aluno com NEEs e, por fim, monitorar o processo de ensino-aprendizagem através de medidas padronizadas e informais de desempenho para se alcançar um percurso educacional bem sucedido.

No contexto brasileiro, considerando-se a falta de diretrizes para nortear os processos de avaliação dos alunos com NEEs, muitas têm sido as questões emergentes: como eles vêm sendo avaliados e identificados como alunos com NEEs? Quais são as definições e critérios adotados para identificá-los? Como é a avaliação para planejar os apoios que os alunos com NEEs precisam? Como é monitorado o rendimento acadêmico dos alunos com NEEs? Eles participam das medidas oficiais padronizadas? Suas notas são computadas na média nacional? Qual é o índice de analfabetismo na população dos alunos com NEEs? Que nível de conhecimentos acadêmicos básicos de leitura, escrita e matemática eles dominam?

E somam-se às preocupações relacionadas ao modelo de AEE baseado nas SRMs e a questão da falta de avaliação do estudante com NEEs, um terceiro aspecto problemático que é a formação de professores de modo geral, mas em particular os professores de Educação Especial que irão fornecer o suporte aos alunos com NEEs nas escolas comuns (MENDES, 2011). Considerando a escassez de cursos de formação de professores especializados que vem sendo supridos com cursos de educação a distância de curta duração e a complexidade do atendimento em SRMs, onde é 
esperado que o professor atenda quaisquer tipos de alunos com NEEs, questiona-se: como e onde os professores que atuam nas SRMs estão sendo formados? Sentem-se aptos para oferecer o AEE, com toda a complexidade preconizada pela atual política de Educação Especial? Como os atuais 55 mil professores serão substituídos no futuro, num contexto de formação precária e

que possivelmente continua mantendo o amadorismo na área, cuja necessidade de "formação emergencial" parece que se perenizou em função da falta de uma proposta política que dê conta da formação inicial?

\section{Definindo a metodologia}

Delimitado o foco do estudo, que seria o Atendimento Educacional Especializado oferecido nas salas de recursos multifuncionais e especificados os três eixos de análise deste AEE (a avaliação dos alunos, a formação dos professores e a organização do ensino), decidiu-se que os participantes deveriam ser os professores especializados que atuavam nas SRMs e que a pesquisa seria do tipo colaborativa, que em sua acepção original significa fazer pesquisa "com" os professores e não "sobre" eles (LIEBERMAN, 1986).

A pesquisa colaborativa insere-se no conjunto de práticas de pesquisa de caráter participativo, sendo que tais práticas têm recebido na literatura diferentes denominações: pesquisa-ação, pesquisa-ação-colaborativa, pesquisa participante, pesquisa em parceria, etc. As fronteiras entre essas diferentes práticas de pesquisa e no interior de uma mesma categoria não são estanques e nem deveriam ser, pois representam, de certa maneira, as ênfases particulares em determinados aspectos (DESGAGNÉ et al., 2001).

Segundo Catelli (1995), a ideia de colaboração na pesquisa surgiu no contexto educacional americano e derivou da tradicional pesquisa-ação surgida no final dos anos de 1960 e 1970 com os trabalhos implicando os atores do próprio contexto e, no caso da pesquisa educacional, as equipes de professores, como forma privilegiada de assegurar o desenvolvimento profissional de todos os envolvidos. No final da década de 1980, as críticas sobre o distanciamento entre a academia e as escolas apontaram para processos de construção de conhecimentos mais ajustados às necessidades da prática, o que envolveria uma maior aproximação entre os pesquisadores e profissionais da educação. Tal contexto agregaria ao sentido inicial dado à colaboração que era o de favorecer o trabalho conjunto entre professores formando-se uma comunidade reflexiva num dado contexto escolar; um segundo sentido, seria o de favorecer uma reaproximação entre pesquisadores universitários e professores. 
Essa história aportou dois ângulos à pesquisa colaborativa. De uma parte, tem-se a ênfase no desenvolvimento profissional dos professores da equipe da escola, e aqui se trata especificamente de formação continuada para encorajar os professores a examinar suas próprias práticas, refiná-las, e se mobilizarem em torno dos problemas que enfrentam na realidade escolar contemporâneam, etc. De outra parte, ao insistir na reaproximação entre professores universitários e professores práticos, direciona-se para reduzir o fosso entre teoria e prática, entre conhecimentos acadêmicos e conhecimentos para a ação. Assim, são esses dois aspectos fundamentais que caracterizam a pesquisa colaborativa: formação e pesquisa.

A pesquisa colaborativa é prevista em três níveis, a saber: Município, Estado e Federação. No âmbito da Federação, foi proposta uma rede nacional de pesquisa composta por até três pesquisadores por estado. Nesse nível da rede, os coordenadores estaduais reunir-se-ão sistematicamente após os encontros estaduais, com a finalidade de analisar os dados dos encontros estaduais. A cada encontro, um documento contendo uma análise será elaborado e este documento será analisado posteriormente nos âmbitos estaduais e locais.

$\mathrm{Na}$ esfera dos estados, foram propostas redes estaduais de pesquisa com pesquisadores das universidades interessados em conduzir estudos em sua localidade. Em nível dos municipal, a proposta é de compor a rede de pesquisa local envolvendo o (s) pesquisadore (s) da universidade que integram a rede estadual, os professores de salas de recursos multifuncionais e, sempre que possível, gestores municipais da educação comum e especial. Os trabalhos serão realizados mediante a organização de grupos de trabalhos coletivos e entrevistas com grupos focais baseados em encontros sistemáticos da rede.

Assim, definido o projeto de constituição do ONEESP e o estudo inaugural, estes foram submetidos a um conjunto de pesquisadores da área, que não só aderiram prontamente à proposta, como também a encaminharam a colegas visando a ampliar a rede, de modo que a proposta enviada ao Edital do Programa Observatório da Educação - Edital 2010 - Fomento a Estudos e Pesquisas em Educação (Edital No 38/2010/Capes/Inep), que foi posteriormente aprovada, contou com uma rede de 25 pesquisadores e o Oneesp começou, então, a tornar-se realidade. 


\section{CONSIDERAÇÕES FINAIS}

Com vimos, diante do atual contexto da política de inclusão escolar brasileira, duas grandes questôes mobilizavam a atenção dos pesquisadores nacionais nos frequentes fóruns de discussão da área de Educação Especial:

- como produzir conhecimento para avançar as políticas e práticas de inclusão escolar no país?

- como melhorar a articulação entre o conhecimento que vem sendo produzido e as decisões nas políticas educacionais relacionadas à perspectiva de inclusão escolar?

Foi pensando nessas questóes que emergiu a ideia de fomentar a implantação de uma rede nacional de pesquisadores da área de Educação Especial e da instituição do Observatório Nacional da Educação Especial (Oneesp), com foco na produção de estudos integrados sobre políticas e práticas direcionadas para a questão da inclusão escolar na realidade brasileira.

A meta com a criação do Oneesp era a de constituir uma rede cooperativa entre pesquisadores, tendo como meta potencializar a produção de informações e conhecimentos necessários para melhorar as decisões em matéria de políticas de inclusão escolar dos sistemas educacionais, além de oportunizar o compartilhamento de experiências entre pesquisadores para aperfeiçoar a sistemática de produção de conhecimento e de desenvolvimento de pessoal na área de Educação Especial.

Hoje, a rede nacional é composta por 36 pesquisadores de 16 estados (Alagoas, Amapá, Amazonas, Bahia, Espírito Santo, Goiás, Mato Grosso do Sul, Minas Gerais, Pará, Paraíba, Paraná, Rio de Janeiro, Rio Grande do Norte, Santa Catarina, São Paulo e Sergipe), 20 instituições de ensino superior e 18 programas de pós-graduação. Considerando os três níveis, um ano após ser criado, integra hoje o Oneesp um total de 211 pesquisadores, incluindo pesquisadores de universidades, pós-doutorandos, alunos de pós-graduação (doutorandos e mestrandos) e de graduação. $\mathrm{O}$ estudo inaugural já foi iniciado e deverá ser concluído nos próximos dois anos. Esperam-se como resultados do projeto:

- coletar e sistematizar informações municipais que subsidiem tomadas de decisões para as políticas de inclusão escolar locais, permitindo, por exemplo, identificar demandas para a formação de professores, limites e possibilidades das salas SRMs, monitoração do desempenho dos alunos com NEEs na escola, etc.;

- ampliar o impacto do conhecimento científico na definição das políticas de inclusão 
escolar nos municípios, nos estados e no país;

- prover formação sobre AEE e SRMs a todos os pesquisadores e professores envolvidos no estudo;

- fortalecer a produção científica nacional na área de Educação Especial por meio da rede de cooperação técnico-científica entre pesquisadores;

- prover formação continuada para mais de 2000 professores especializados que atuam em salas de recursos de escolas públicas;

- e, finalmente, prover a oportunidade de intercâmbio e formação entre os integrantes dos grupos de pesquisa das 18 universidades.

\section{REFERÊNCIAS}

BRASIL. Constituição Federal. Brasília - DF, 1988.

BRASIL. Decreto ${ }^{\circ}$ 6.571, de 17 de setembro de 2008. Dispõe sobre o atendimento educacional especializado. Presidência da República/Casa Civil/Subchefia para Assuntos Jurídicos. Brasília, 2008.

BRASIL. Lei n 9.394, de 20 de dezembro de 1996. Estabelece as diretrizes e bases da educação nacional. Diário Oficial [da] República Federativa do Brasil, Brasília, 23 de dez. 1996. Seção 1, 1996.

BRASIL. Política de Educação Especial na perspectiva da Educação Inclusiva. Disponível em http://portal.mec.gov.br/arquivos/pdf/politicaeducespecial.pdf. Ministério da Educação/ Secretaria de Educação Especial. 2007. Acesso em 24/março de 2008.

CAPELLINI, V.M.F. A inclusão de alunos com necessidades educacionais especiais em classes comuns: Avaliação do rendimento acadêmico. 2001. Dissertação de Mestrado, Programa de Pós-Graduação em Educação Especial, Universidade Federal de São Carlos, São Carlos, 2001.

CATELLI, L.A. Action research and collaborative inquiry in a school-university partnership. Action in Teacher Education, v. 16, n.4 , p. 25-38, 1995.

DESGAGNÉ, S.; BEDNARZ, N.; LEBUIS, P.; POIRIER L.; COUTURE, C. .L'approche collaborative de recherche en éducation: Un rapport nouveau à établir entre recherche et formation. Revue des sciences de l'éducation, v. 27, n.1, p. 33-64, 2001.

DORN, S.; FUCHS, D.; FUCHS, L. S. A historical perspective on special education reform. Theory Into Practice, v. 35, p. 12-19. 1996. 
DOWNING, J. E.; EICHINGER, J.;WILLIAMS, L. J. Inclusive education for students with severe disabilities: Comparative views of principals and educators at different levels of implementation. Remedial and Special Education, v. 18, p. 133-142, 1997.

EUROPEAN AGENCY. Special Education across Europe in 2003. 2003. Disponível em: <http://www.european-agency.org/publications > acesso em: 05-08-2008.

FERGUSON, D. L.Is it inclusion yet? Bursting the bubbles. In: BERRES, M.S.; FERGUSON, D.L.; KNOBLOCK, P.; \& WOODSS, C. (Eds.), Creating tomorrow's schools today: Stories of inclusion, change, and renewal. New York: Teachers College Press, 1996. p. 16-37.

GIL, J.; PRIETO, R. G. ; SOTO, A. P. O. M.; FREITAS, A. P. R.; GRINKRAUT, A.; ZICHIA, A. C.; BARBOSA, L. M. R.; CURSINO, P. R.; GONZALEZ, R. K. Gestão das políticas de atendimento aos alunos com necessidades educacionais especiais em municípios paulistas. Jornal de Políticas Educacionais, v. 4, p. 15-24, 2010.

IDOL, L. Key questions related to building collaborative and inclusive schools. Journal of Learning Disabilities, v. 30, p. 384-394, 1997.

JESUS, D. M. ; VIEIRA, A. B. ; MILANESI, J. B. Cartografando políticas públicas de educação especial na perspectiva da inclusão escolar: de que dispositivos de atendimentos dispomos no estado do espírito santo? Cadernos ANPAE, v. 08, p. 1-12, 2009.

JESUS, D. M.; GONCALVES, A. F. A política de parceria para inclusão escolar nos municípios do estado do espírito santo. Cadernos ANPAE, v. 08, p. 1-12, 2009

KAVALE, K.A.; FORNESS, S.R. History, Rhetoric, and Reality Analysis of the Inclusion Debate. Remedial and Special Education, v. 21, n. 5, p. 279-296, 2000.

LIEBERMAN, A.Collaborative research: Working with, not working on... Educational Leadership, v. 43, n. 5, p. 29-32, 1986.

MENDES, E. G. A formação do professor e a política nacional de Educação Especial. In: Anais do V Seminário Nacional de Pesquisa em Educação Especial, 2009, São Paulo. V Seminário Nacional de Pesquisa em Educação Especial, 2009. v. 1. p. 1-15

MENDES, E. G. Pesquisas sobre Inclusão Escolar: Revisão da Agenda de um Grupo de Pesquisa. Revista Eletrônica de Educação, v. 2, p. 1-11, 2008.

MENDES, E.G. A Formação do Professor e a Política Nacional de Educação Especial. In: CAIADO, K. R.M.; JESUS, D.M.; BAPTISTA, C.R. (Org.). Professores e Educação Especial - formação em foco. Editora Mediação: Porto Alegre, 2011.p. 131-146 
MENDES, E. G.; et al.

MEREDITH, B.;UNDERWOOD, J. Irreconcilable differences? Defining the rising conflict between regular and special education. Journal of Law and Education, v24, p. 195-226. 1995.

PRIETO, R. G.; SOUSA, S. M. Z. L. Educação especial: O atendimento em salas de recursos na rede municipal de São Paulo. Educação, v. 32, p. 375-396, 2007

SOWELL, T. The vision of the anointed: Self-congratulation as a basis for social policy. New York: Basic Books, 1995.

TANNÚS-VALADÃO, G. Planejamento educacional individualizado: Propostas oficiais da Itália, França, Estados Unidos e Espanha. 2010. 130f. Dissertação de Mestrado. Programa de Pós-Graduação em Educação Especial, Universidade Federal de São Carlos, São Carlos, 2010.

TEIXEIRA, E. Identificação de barreiras para a escolarização inclusiva de alunos com deficiências físicas. 2009. 140f. Dissertação de Mestrado. Programa de Pós-Graduação em Educação Especial, Universidade Federal de São Carlos, São Carlos, 2009.

VELTRONE, A.A. Inclusão escolar do aluno com deficiência intelectual no Estado de São Paulo: Identificação e caracterização. 2011. 193f. Tese de Doutorado, Programa de PósGraduação em Educação Especial, Universidade Federal de São Carlos, São Carlos, 2011.

WANG, M.; REYNOLDS, M.; WALBERG, H. Handbook of Special Education: research and practice. Oxford: Emerald Group Publishing Limited, 1995.

Submetido em: 03/2012

Aprovado em: 05/2012 